\title{
A bionic system with Fenton reaction and bacteria as a model for bioprocessing lignocellulosic biomass
}

Kejing Zhang ${ }^{1,2}$, Mengying Si ${ }^{1,2}$, Dan Liu ${ }^{1,2}$, Shengnan Zhuo ${ }^{1,2}$, Mingren Liu ${ }^{1,2}$, Hui Liu ${ }^{1,2}$, Xu Yan ${ }^{1,2^{*}}$ and $\operatorname{Yan} \mathrm{Shi}^{1,2^{*}}$

\begin{abstract}
Background: The recalcitrance of lignocellulosic biomass offers a series of challenges for biochemical processing into biofuels and bio-products. For the first time, we address these challenges with a biomimetic system via a mild yet rapid Fenton reaction and lignocellulose-degrading bacterial strain Cupriavidus basilensis B-8 (here after B-8) to pretreat the rice straw (RS) by mimicking the natural fungal invasion process. Here, we also elaborated the mechanism through conducting a systematic study of physicochemical changes before and after pretreatment.

Results: After synergistic Fenton and B-8 pretreatment, the reducing sugar yield was increased by $15.6-56.6 \%$ over Fenton pretreatment alone and 2.7-5.2 times over untreated RS $\left(98 \mathrm{mg} \mathrm{g}^{-1}\right)$. Morphological analysis revealed that pretreatment changed the surface morphology of the RS, and the increase in roughness and hydrophilic sites enhanced lignocellulose bioavailability. Chemical components analyses showed that B-8 removed part of the lignin and hemicellulose which caused the cellulose content to increase. In addition, the important chemical modifications also occurred in lignin, 2D NMR analysis of the lignin in residues indicated that the Fenton pretreatment caused partial depolymerization of lignin mainly by cleaving the $\beta-0-4$ linkages and by demethoxylation to remove the syringyl (S) and guaiacyl (G) units. B-8 could depolymerize amount of the $G$ units by cleaving the $\beta-5$ linkages that interconnect the lignin subunits.

Conclusions: A biomimetic system with a biochemical Fenton reaction and lignocellulose-degrading bacteria was confirmed to be able for the pretreatment of RS to enhance enzymatic hydrolysis under mild conditions. The high digestibility was attributed to the destruction of the lignin structure, partial hydrolysis of the hemicellulose and partial surface oxidation of the cellulose. The mechanism of synergistic Fenton and B-8 pretreatment was also explored to understand the change in the RS and the bacterial effects on enzymatic hydrolysis. Furthermore, this biomimetic system offers new insights into the pretreatment of lignocellulosic biomass.
\end{abstract}

Keywords: Lignocellulose pretreatment, Cupriavidus basilensis B-8, Fenton reaction, Enzymatic hydrolysis

\section{Background}

Most terrestrial biomass is sequestered in lignocellulose-the principal structural material in vascular plants. Accordingly, the biological decomposition of lignocellulosic materials plays an essential role in carbon cycling in terrestrial forested ecosystems $[1,2]$. Simultaneously,

\footnotetext{
*Correspondence: yanxu1202@csu.edu.cn; shiyzyrs@csu.edu.cn

1 School of Metallurgy and Environment, Central South University, Changsha 410083, People's Republic of China

Full list of author information is available at the end of the article
}

lignocellulose is one of the richest renewable resources on the earth. Its biodegradation has been studied not only as an ecological process, but also in the context of both the development of environmentally friendly agricultural waste disposal processes and the production of "green" and renewable fuels and chemicals [3-5].

In nature, few organisms can metabolize lignocelluloses, because it has cellulose and hemicelluloses-components that can support microbial growth-embedded in lignin [6]. Lignin is a combinatorial and racemic polymer 
containing phenylpropanoid subunits connected via ether and carbon-carbon bonds [7]. These provide structural support and resistance for the plant cell wall against microbial attack and oxidative stress [8,9]. Any organism that depends on lignocellulose as a source of carbon and energy must have some mechanisms to penetrate or disrupt this recalcitrant lignin barrier.

Thus far, studies on the biodegradation of lignocellulose have mainly focused on fungi. Wood decay basidiomycetes are the most efficient biodegraders of lignocellulose. They can break down and/or mineralize lignin with the help of two systems viz $[10,11]$. However, the disadvantages of fungal pretreatment strategies are their low efficiency, considerable loss of carbohydrates and long residence times [12]. Although the microbial degradation of lignin has been most intensively studied in white-rot and brown-rot fungi, there are many reports of bacteria that are isolated from soil, wastewater, pulp, and black liquor that can decompose lignin [13, 14]. Compared to fungi, bacteria have a shorter growth cycle and stronger tolerance to harsh industrial conditions. However, bacteria generally only modify lignin or metabolize low molecular weight components of lignin [15]. Therefore, bacterial pretreatment to break lignin's recalcitrance to lignocellulose is rarely reported.

As shown in nature, there are symbioses between bacteria and fungi for using lignocellulose. The fungi break the recalcitrant cell wall barrier and release the small molecular compounds that then become available for further degradation and assimilation by commensal bacteria $[16,17]$. This interdependence of microbes is a key link in the turnover of nutrients and carbon in forest ecosystems. This symbiotic system provides a new idea for the use of lignin-degrading bacteria to treat natural lignocellulose. To shorten the long-term lignocellulose pretreatment by fungi, we considered replacing this pretreatment with new methods. Compared with white-rot fungi, which has a complete lignin-degrading enzyme system, brown-rot fungi harbor an oxidative radicalbased system that causes non-enzymatic disruption of lignocellulose [18]. This oxidative step modifies the plant cell wall via the action of highly destructive oxygenderived free radicals, such as the highly reactive hydroxyl radical $(\cdot \mathrm{OH})$, produced by extracellular Fenton chemistry $\left(\mathrm{Fe}^{2+}\right.$ and $\left.\mathrm{H}_{2} \mathrm{O}_{2}\right)$. Hence, the biochemical mechanism of brown-rot fungi is an alternative to the energetic apparatus of lignocellulose breakdown employed by white-rot fungi. A few researchers have reported that the Fenton reaction induced by chemical reagents can reduce the molecular weight of lignin and enhance enzymatic saccharification of lignocellulosic biomass [19]. Moreover, Fenton reactions occur under mild conditions, and thus it is considered as an environmentally friendly process $[20,21]$.

In our previous work, Cupriavidus basilensis B-8 (here after B-8), isolated from the steeping fluid of eroding bamboo slips, was identified as a potential bacterium for lignin degradation [22]. Here, inspired by natural lignocellulose degradation systems, we hope to combine mild chemical pretreatment with B-8 to rapidly simulate fungal invasion of plant tissue. Herein, we used a low-cost Fenton catalyst $\left(\mathrm{Fe}^{3+}\right.$ and $\mathrm{H}_{2} \mathrm{O}_{2}$ ) to pretreat the selected model of lignocellulosic biomass (rice straw, RS), and then combined it with B-8 to form a biomimetic system that then enhanced enzymatic hydrolysis. This biochemical model is of interest to lignocellulose biorefineries for the sustainable production of chemicals, materials and fuels from renewable plant resources, which are more cost-effective and energy efficient.

\section{Methods}

\section{Microorganism and RS}

The bacterial strain B-8 had been deposited in the China General Microbiological Culture Collection Center (CGMCC) with an accession number of CGMCC 4240. Pure B-8 was cultured aerobically on a rotary shaker at $30{ }^{\circ} \mathrm{C}$ with a speed of $125 \mathrm{rpm}$ in Luria-Bertani broth medium for $18 \mathrm{~h}$. The culture was used as seed culture for biological pretreatment. RS used in all the experiments was obtained from Jining (Shandong, China). RS was ground into powder, air-dried, and then sifted by 60-mesh first and then 100-mesh griddles to make sure the size of the obtained RS was between 150 and $250 \mu \mathrm{m}$. The processed RS was used as the feedstock for the pretreatment.

\section{Solution phase Fenton pretreatment}

RS pretreatment by the Fenton catalyst was performed in an Erlenmeyer flask at room temperature with stirring at $120 \mathrm{rpm}$. The Fenton reagent $\left(\mathrm{FeCl}_{3}, \mathrm{FeCl}_{2} \cdot 4 \mathrm{H}_{2} \mathrm{O}\right.$, and $\mathrm{H}_{2} \mathrm{O}_{2}$ ) was added to the RS suspension at a solid loading of $10 \%(\mathrm{w} / \mathrm{v})$ to initiate the reaction. After incubation for $2 \mathrm{~h}$, the pretreated RS slurry was washed with deionized water until the $\mathrm{pH}$ of the filtrate reached 6-7; it was then dried at $55{ }^{\circ} \mathrm{C}$ for $12 \mathrm{~h}$ for further analysis. The concentration and the ratio of the constituents of Fenton's reagent (i.e., $\mathrm{FeCl}_{2}, \mathrm{FeCl}_{3}$, and $\mathrm{H}_{2} \mathrm{O}_{2}$ ) are key parameters in the Fenton reaction. $\mathrm{FeCl}_{3}, \mathrm{FeCl}_{2}$ and $\mathrm{H}_{2} \mathrm{O}_{2}$ were diluted to the desired concentrations that the ratio of Fe to $\mathrm{H}_{2} \mathrm{O}_{2}$ was 1:75 [21], and then set a series of concentration gradients on this basis. The optimal concentration of $\mathrm{FeCl}_{2}$ was investigated as the control group. Fenton- $\mathrm{A}$ is $0.04 \mathrm{M}$ $\mathrm{FeCl}_{3}$ and $3 \mathrm{M} \mathrm{H}_{2} \mathrm{O}_{2}$, Fenton- $\mathrm{B}$ is $0.03 \mathrm{M} \mathrm{FeCl}_{3}$ and $2.25 \mathrm{M} \mathrm{H}_{2} \mathrm{O}_{2}$, Fenton-C is $0.02 \mathrm{M} \mathrm{FeCl}_{3}$ and $1.5 \mathrm{M} \mathrm{H}_{2} \mathrm{O}_{2}$, 
Fenton-D is $0.01 \mathrm{M} \mathrm{FeCl}_{3}$ and $0.75 \mathrm{M} \mathrm{H}_{2} \mathrm{O}_{2}$, and Fenton$\mathrm{E}$ is $0.02 \mathrm{M} \mathrm{FeCl}_{2}$ and $1.5 \mathrm{M} \mathrm{H}_{2} \mathrm{O}_{2}$. All the chemicals were analytical grade and purchased from Sinopharm Chemical Reagent Co., Ltd., of China.

\section{Bacterial pretreatment with B-8}

The biological pretreatment was carried out in a $500 \mathrm{~mL}$ Erlenmeyer flask with $2 \mathrm{~g}$ of RS and $200 \mathrm{~mL}$ of mineral salt medium. The composition of the mineral salt medium was as follows ( $\mathrm{g} \mathrm{L}^{-1}$ in de-ionized water): $\left(\mathrm{NH}_{4}\right)_{2} \mathrm{SO}_{4}, 2 ; \mathrm{K}_{2} \mathrm{HPO}_{4}, 1 ; \mathrm{MgSO}_{4}, 0.2 ; \mathrm{CaCl}_{2}, 0.1 ; \mathrm{FeSO}_{4}$, $0.05 ; \mathrm{MnSO}_{4}, 0.02 ; \mathrm{KH}_{2} \mathrm{PO}_{4}, 1 ; \mathrm{pH}$ 7.0. Here, $20 \mathrm{~mL}$ of the bacterial culture was centrifuged, and the collected cells were inoculated into the medium. The biological pretreatment used a gas bath shaker at $30{ }^{\circ} \mathrm{C}$ with a speed of $125 \mathrm{rpm}$. After 2 days of incubation, the bio-treated RS sample was collected and thoroughly washed with deionized water. It was then dried at $50{ }^{\circ} \mathrm{C}$ for further experiments.

\section{Enzymatic saccharification}

Commercial cellulase Cellic (CTec2, Novozymes) with 12 filter paper units (FPU) $\mathrm{g}^{-1}$ biomass was used for enzymatic hydrolysis. The $0.5 \mathrm{~g}$ of RS were added to $20 \mathrm{~mL}$ of citrate buffer $(50 \mathrm{mM}, \mathrm{pH} 4.8)$ supplemented with cycloheximide $\left(20 \mu \mathrm{g} \mathrm{mL} \mathrm{m}^{-1}\right)$ and tetracycline $\left(20 \mu \mathrm{g} \mathrm{mL}^{-1}\right)$ to prevent microbial contamination. $30 \mu \mathrm{L}$ of cellulase was loaded into the mixture to start the reaction in a shaking incubator with the speed of $120 \mathrm{rpm}$ at $50{ }^{\circ} \mathrm{C}$ for $72 \mathrm{~h}$. After incubation, samples were collected and centrifuged for sugar analysis. The reducing sugar was measured via the DNS assay [23].

\section{Chemical composition measurement of RS}

The chemical composition of the RS was determined according to the chemical analysis methods reported by Teramoto et al. [24]. Specifically, holocellulose content was determined via weighting the $\mathrm{NaClO}_{2}$-delignified residue; cellulose content was determined via weighting the insoluble residue of holocellulose in the $17.5 \%$ $\mathrm{NaOH}$ aqueous solution; lignin content was determined via weighting the insoluble residue in $72 \%$ sulfuric acid aqueous solution. All experiments were carried out in triplicate.

\section{Analytical methods}

Scanning electron microscope (SEM): Samples obtained from various pretreatments coated with gold using a sputter coater were observed under a SEM (JSM-IT300LA, JEOL, Japan); atomic force microscopy (AFM): AFM was performed in tapping mode on a NanoManTM VS + MultiMode V scanning probe microscope (Veeco Company, USA); BET specific surface area test method (BET): The size distribution of RS was characterized using a Malvern Mastersizer 2000 particle size analyzer (Malvern Instruments, UK). X-ray diffraction (XRD): XRD method was used to detect the RS crystallinity index (CrI) using a TTR III X-ray diffractometer (Rigaku, Japan). The RS powders were laid on the glass sample holder and were analyzed under plateau conditions. The $\mathrm{Ni}$-filtered $\mathrm{Cu} \mathrm{K} \alpha$ radiation $(\lambda=0.154056 \mathrm{~nm})$ was generated at $40 \mathrm{kV}$ and a current of $18 \mathrm{~mA}$. and the scan speed was $2^{\circ} \mathrm{s}^{-1}$ from $10^{\circ}$ to $40^{\circ}[25,26]$. CrI was calculated using the following equation:

$$
\text { Crystallinity }=\left[\left(I_{002}-I_{\mathrm{amp}}\right) / I_{002}\right]
$$

where $I_{002}$ is the intensity of the (002) peak at about $2 \theta=22.1^{\circ}$, and $I_{\mathrm{amp}}$ is the intensity of the background at about $2 \theta=16.1^{\circ}$; Fourier transform infrared spectroscopy (FTIR): The background spectrum of pure potassium bromide was subtracted from that of the sample spectrum. The FTIR spectra of the samples were obtained with analysis performed on a 1760X Fourier transform infrared spectrometer (PerkinElmer, Shanghai, China) from 4000 to $500 \mathrm{~cm}^{-1}$; 2D-nuclear magnetic resonance (2D-NMR): Studies on lignin from RS were performed according to Wen et al. [27]. Lignin (40 mg) was dissolved in anhydrous pyridine $(500 \mathrm{~mL})$ and deuterated chloroform $(1.6: 1, \mathrm{v} / \mathrm{v})$ along with $N$ hydroxynaphthalimide $(200 \mathrm{~mL})$ as an internal standard $\left(11.4 \mathrm{mg} \mathrm{mL}^{-1}\right.$ in pyridine and deuterated chloroform) and chromium acetylacetonate $(0.28 \mathrm{mg})$. Next, the phosphitylating reagent 2-chloro-1,3, 2-dioxaphospholane $(100 \mathrm{~mL})$ was added. The mixture was stirred for $10 \mathrm{~min}$ and subjected to Bruker (Billerica, MA) AVIII $500 \mathrm{MHz}$ NMR spectrometer spectra.

\section{Results and discussion}

\section{Effects of pretreatments on enzymatic hydrolysis}

To determine the feasibility of this bionic method, RS was treated with only the Fenton reaction, synergistic Fenton and B-8 pretreatment (Fenton + B-8), or synergistic B-8 and Fenton pretreatment (B-8 + Fenton). Herein, the digestibility of untreated and pretreated RS were presented in Fig. 1. During the Fenton pretreatment, $\mathrm{H}_{2} \mathrm{O}_{2}$ was first decomposed into hydroxyl or perhydroxyl radicals when the transition metal $\left(\mathrm{Fe}^{3+} / \mathrm{Fe}^{2+}\right)$ presented. Then, the radicals randomly attacked the cell wall and caused lignocellulose structure breakdown. Generally, Fenton reaction was described as the following two reaction phases:

$$
\begin{aligned}
& \mathrm{Fe}^{2+}+\mathrm{H}_{2} \mathrm{O}_{2} \rightarrow \mathrm{Fe}^{3+}+\mathrm{OH}+\mathrm{OH}^{-} \\
& \mathrm{Fe}^{3+}+\mathrm{H}_{2} \mathrm{O}_{2} \rightarrow \mathrm{Fe}^{3+}-\mathrm{OOH}^{2+}+\mathrm{H}^{+}
\end{aligned}
$$




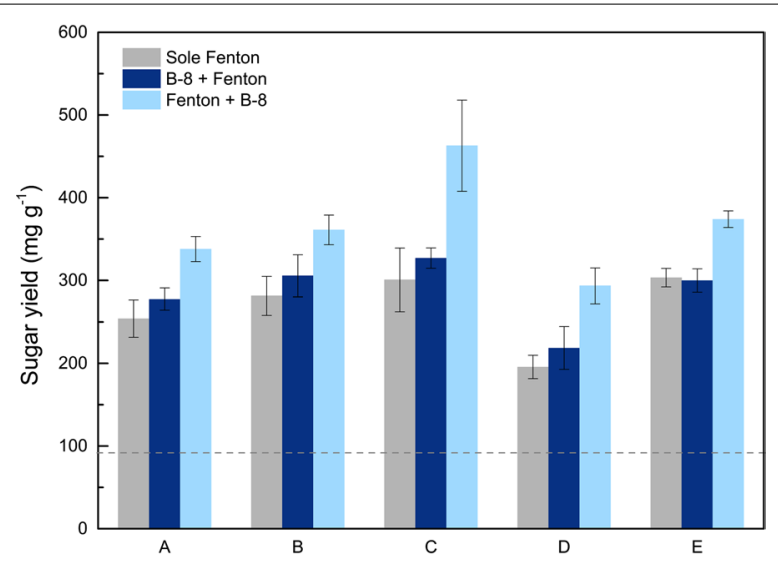

Fig. 1 The effect of pretreatment conditions on the enzymatic hydrolysis of the pretreated RS. The sugar yield of untreated RS was pointed out with dashed line. The experimental groups Fenton- $\mathrm{A}$ is $0.04 \mathrm{M} \mathrm{FeCl}_{3}$ and $3 \mathrm{M} \mathrm{H}_{2} \mathrm{O}_{2}$, Fenton- $\mathrm{B}$ is $0.03 \mathrm{M} \mathrm{FeCl}_{3}$ and $2.25 \mathrm{M} \mathrm{H}_{2} \mathrm{O}_{2}$, Fenton- $\mathrm{C}$ is $0.02 \mathrm{M} \mathrm{FeCl}_{3}$ and $1.5 \mathrm{M} \mathrm{H}_{2} \mathrm{O}_{2}$, Fenton- $\mathrm{D}$ is $0.01 \mathrm{M} \mathrm{FeCl}_{3}$ and $0.75 \mathrm{M} \mathrm{H}_{2} \mathrm{O}_{2}$, and Fenton- $\mathrm{E}$ is $0.02 \mathrm{M} \mathrm{FeCl}_{2}$ and $1.5 \mathrm{M} \mathrm{H}_{2} \mathrm{O}_{2}$

$$
\begin{aligned}
& \mathrm{Fe}^{3+}-\mathrm{OOH}^{2+} \rightarrow \mathrm{Fe}^{2+}+\mathrm{HO}_{2} \cdot \\
& \mathrm{Fe}^{2+}+\mathrm{H}_{2} \mathrm{O}_{2} \rightarrow \mathrm{Fe}^{3+}+\cdot \mathrm{OH}+\mathrm{OH}^{-} \\
& \mathrm{Fe}^{2+}+\mathrm{HO}_{2} \cdot+\mathrm{H}^{+} \rightarrow \mathrm{Fe}^{3+}+\cdot \mathrm{H}_{2} \mathrm{O}_{2} \\
& \mathrm{Fe}^{3+}+\mathrm{HO}_{2} \cdot \rightarrow \mathrm{Fe}^{2+}+\mathrm{O}_{2}+\mathrm{H}^{+}
\end{aligned}
$$

In the first phase, $\mathrm{Fe}^{2+}$ initiates and catalyzes the decomposition of $\mathrm{H}_{2} \mathrm{O}_{2}$ rapidly and results in the generation of $\cdot \mathrm{OH}$. Meanwhile, $\mathrm{Fe}^{3+}$ gives rise to a complex chain reaction sequence. In contrast to the first reaction phase, the second phase is several orders of magnitude slower. Herein, we used the $\mathrm{Fe}^{3+}$ to reduce $\mathrm{H}_{2} \mathrm{O}_{2}$ into free $\mathrm{OOH}$ radicals under mild conditions. After pretreatment, the residues were subsequently submitted to enzymatic hydrolysis for $72 \mathrm{~h}$. The RS pretreated with only $\mathrm{H}_{2} \mathrm{O}_{2}$ or only $\mathrm{Fe}(\mathrm{II}) / \mathrm{Fe}(\mathrm{III})$ was not effectively hydrolyzed by the cellulase (Additional file 1: Figure S1).
In contract, the reducing sugar yields per gram of RS varied from 180.4 to $332.6 \mathrm{mg} \mathrm{g}^{-1}$, which were $1.8-3.4$ times higher than that from untreated RS $\left(\sim 98 \mathrm{mg} \mathrm{g}^{-1}\right.$, dashed line). This was primarily due to the destruction of the recalcitrant structure of the biomass, which improved the substrate hydrolyzability by enzymes. This indicated that Fenton pretreatment can imitate the rapid fungal invasion observed in natural symbiotic systems. More significantly, there was a universal improvement (15.6-56.6\%) over Fenton pretreatment alone with Fenton + B-8 pretreatment. Higher digestibility (270.5-514.1 $\mathrm{mg} \mathrm{g}^{-1}$ ) that was 2.7-5.2 times higher than untreated RS was obtained. In addition, the saccharification was weakened at higher concentrations of Fenton reagents. Similar results were obtained after B- 8 pretreatment. This phenomenon was due to Fenton reaction that was too strong at higher concentrations which can severely damage the cellulose matrix [19]. The maximum production of sugars was obtained with $0.02 \mathrm{M} \mathrm{FeCl}_{3}$ and $1.5 \mathrm{M} \mathrm{H}_{2} \mathrm{O}_{2}$. The average yield of the reducing sugar increased 4.71-fold compared with untreated RS. This suggested that the synergistic B-8 and Fenton pretreatment greatly improve enzymatic hydrolysis under mild conditions; on the other hand, free $\cdot \mathrm{OOH}$ radicals produced by $\mathrm{Fe}^{3+}$ catalysis that were milder than the free $\cdot \mathrm{OH}$ radicals produced by $\mathrm{Fe}^{2+}$ catalysis were suitable for RS pretreatment. Table 1 summarizes the recent reports of Fenton reaction pretreatment and combined biological and chemical pretreatments. It showed that our improvements were quite competitive with methods described in the literature. Notably, the Fenton pretreatment was conducted at room temperature without external energy input, and the bacterial pretreatment required much less time than fungal pretreatments [28]. Accordingly, the Fenton + B-8 pretreatment was highly competitive over other biological pretreatments.

The results of synergistic B-8 and Fenton pretreatment had a yield of reducing sugar that was far lower than the Fenton + B- 8 pretreatment. This indicated that the effect

\begin{tabular}{|c|c|c|}
\hline Biomass & The pretreatment process & The increase of the sugar yield \\
\hline Mixed hardwood [41] & Fenton $\left(\mathrm{FeSO}_{4} 0.1 \mathrm{M}_{1} \mathrm{H}_{2} \mathrm{O}_{2} 2.5 \mathrm{M}, 50{ }^{\circ} \mathrm{C}, 96 \mathrm{~h}\right)+$ hydrothermal treatment $\left(190{ }^{\circ} \mathrm{C}, 10 \mathrm{~min}\right)$ & 3.80-fold \\
\hline Rice straw [21] & Fenton $\left(0.05 \mathrm{M} \mathrm{FeCl}_{3}, 2.5 \mathrm{M} \mathrm{H}_{2} \mathrm{O}_{2}, 25^{\circ} \mathrm{C}, 24 \mathrm{~h}\right)$ & 3.85-fold \\
\hline Cotton stalk [42] & Phanerochaete chrysosporium (fungal, 14 days, $39^{\circ} \mathrm{C}$ ) & $<1$-fold \\
\hline Glycyrrhiza uralensis [28] & $\mathrm{H}_{2} \mathrm{SO}_{4}\left(2.5 \%, 100{ }^{\circ} \mathrm{C}, 180 \mathrm{~min}\right)+$ Phanerochaete chrysosporium (fungal, 21 days, $28^{\circ} \mathrm{C}$ ) & 2-fold \\
\hline Rice straw [43] & $\begin{array}{l}\mathrm{NaOH} / \text { urea }\left(4 \% / 6 \%,-10^{\circ} \mathrm{C}, 240 \mathrm{~min}\right)+\text { Sphingobacterium sp. LD-1 (bacterial, } 4 \text { days, } \\
\left.30^{\circ} \mathrm{C}\right)\end{array}$ & 5.4-fold \\
\hline Rice straw (in this study) & $\begin{array}{l}\text { Fenton }\left(0.02 \mathrm{M} \mathrm{FeCl}_{3}, 1.5 \mathrm{M} \mathrm{H}_{2} \mathrm{O}_{2}, 25^{\circ} \mathrm{C}, 120 \mathrm{~min}\right)+\text { Cupriavidus basilensis B-8 (bacterial, } \\
\left.2 \text { days, } 30^{\circ} \mathrm{C}\right)\end{array}$ & 4.71-fold \\
\hline
\end{tabular}
of sole B-8 treatment was very weak, and it was difficult

Table 1 Comparison of different pretreatments strategies and the increase of sugar yield as compared with the untreated substrate 
for B-8 to break untreated RS. The very positive effect on the reducing sugar yield by Fenton + B- 8 pretreatment showed that the Fenton reaction changed the biomass structure and modified lignin. This facilitated lignin residues that were partly utilized and/or further modified by B-8. Lignin removed by bacteria after Fenton pretreatment further exposed more hemicellulose and cellulose and improved the hydrolysis performance. Fenton pretreatment created conditions for bacterial treatment, validated the feasibility of the model for bioprocessing, and allowed the lignin-degrading bacteria to proceed after chemical pretreatment. Obviously, this bionic method was very different from the real symbiosis system and evolves special mechanism. Next, to explore the mechanism, we carried out a series of detailed characterization steps.

\section{Effects of pretreatments on chemical components}

The untreated RS was found to mainly contain $42 \mathrm{~g}$ of cellulose, $35 \mathrm{~g}$ of hemicellulose and $18 \mathrm{~g}$ of lignin in $100 \mathrm{~g}$ of initial total biomass. The composition of the different chemical components in the residues after various pretreatment steps was seen in Fig. 2. A compositional analysis of the RS after pretreatment using the Fenton's reagent for $2 \mathrm{~h}$ revealed that the amounts of lignin were significantly reduced to $7.8-12.7 \mathrm{~g}$ per $100 \mathrm{~g}$ of initial total RS with the removal rate of 29.4$56.6 \%$, this was probably due to the oxidation of the lignin. The content of the cellulose obviously decreased to $15.8-31.2 \mathrm{~g}$ per $100 \mathrm{~g}$. The Fenton reaction was fast and harsh, and hydrogen peroxide radicals non-selectively attacked the cell walls, results in rapid degradation of the cellulosic substrates. Combined with the results of the previous enzymatic hydrolysis analysis ("Effects of pretreatments on enzymatic hydrolysis" section), Fenton pretreatment decreased the content of cellulose, but generally improved sugar yields. This might be because free radicals produced by the Fenton reaction act on cellulose, resulting in oxidation and the creation of more sites for the cellulases to bind, improving the hydrolysis. However, fiber surface fibrillation generally occurs under mild reaction conditions, pretreatments with high concentrations of Fenton's reagents can cause severe damage to the cellulosic fibers [29]. This also explained why Fenton- $C$ could retain more cellulose and had a better effect on the enzymatic hydrolysis than Fenton-A and Fenton-B with high concentrations of Fenton reagents. Furthermore, relatively high amounts of hemicellulose loss (26-38\%) were also observed under severe pretreatment conditions (Fenton-A, Fenton-B and Fenton-E).

To investigate the effect of Fenton + B-8 pretreatment on the content of major components, RS pretreated with the Fenton reagent was further treated by B-8. As shown in Fig. 2, after B-8 pretreatment, the contents of cellulose, lignin and hemicellulose were adjusted to 14.8-30.6, 5.49.0 and $18.7-31.4 \mathrm{~g}$ in $100 \mathrm{~g}$ of initial total RS, respectively. The results showed that B-8 removed part of the lignin and hemicelluloses while retaining the cellulose. These effects of B- 8 were crucial to obtain high levels of enzymatic digestibilities in the Fenton + B- 8 pretreatment system. These results illustrated that B-8 impacted the pretreatment of the lignocellulosic biomass. Physical and chemical characterization was next performed under optimal conditions (Fenton-C) to elucidate the role of B-8 in the pretreatment.

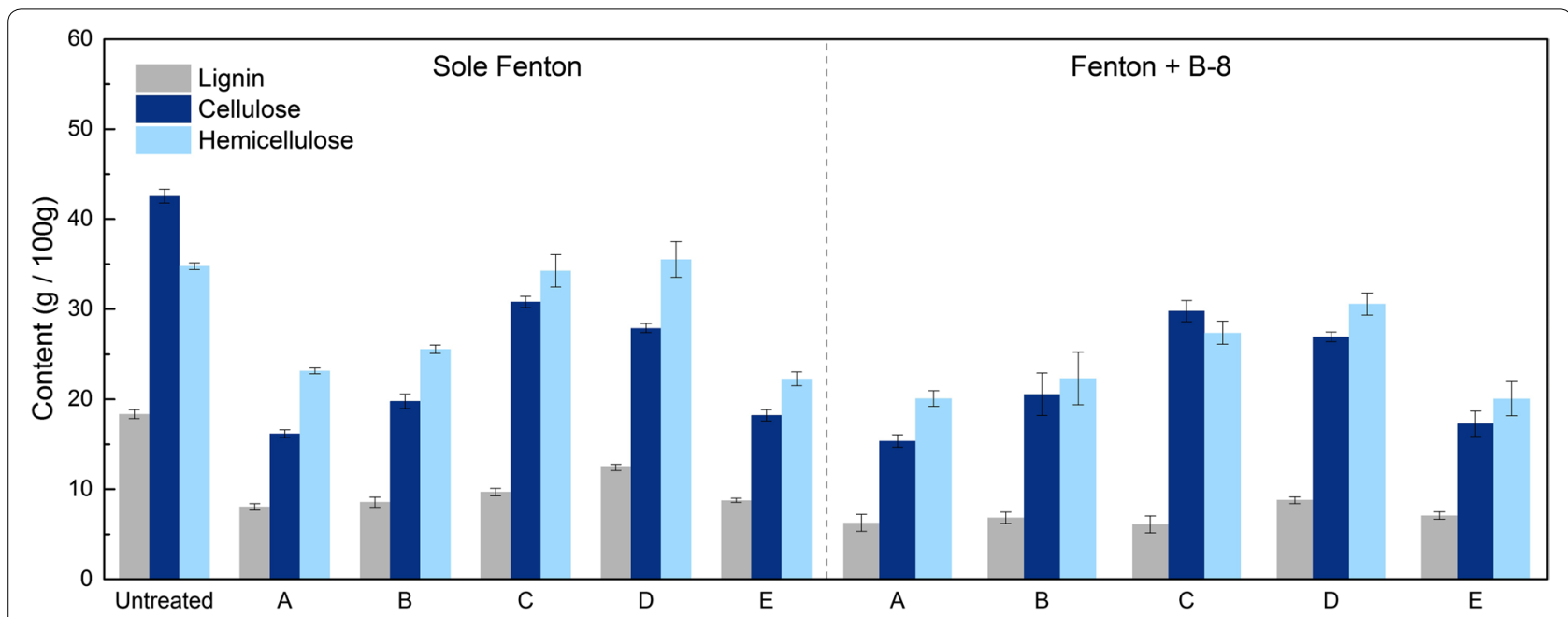

Fig. 2 The effect of pretreatment conditions on the chemical composition of the pretreated RS. The experimental groups Fenton- $\mathrm{A}$ is $0.04 \mathrm{M} \mathrm{FeCl} 3$ and $3 \mathrm{M} \mathrm{H}_{2} \mathrm{O}_{2}$, Fenton- $\mathrm{B}$ is $0.03 \mathrm{M} \mathrm{FeCl}_{3}$ and $2.25 \mathrm{M} \mathrm{H}_{2} \mathrm{O}_{2}$, Fenton- $\mathrm{C}$ is $0.02 \mathrm{M} \mathrm{FeCl}_{3}$ and $1.5 \mathrm{M} \mathrm{H}_{2} \mathrm{O}_{2}$, Fenton-D is $0.01 \mathrm{M} \mathrm{FeCl}_{3}$ and $0.75 \mathrm{M} \mathrm{H}_{2} \mathrm{O}_{2}$, and Fenton- $\mathrm{E}$ is $0.02 \mathrm{M} \mathrm{FeCl}_{2}$ and $1.5 \mathrm{M} \mathrm{H}_{2} \mathrm{O}_{2}$ 


\section{Surface morphology change of RS}

Efficient enzymatic hydrolysis depends on the availability of the cellulose system to cellulase. The removal of lignin and hemicellulose could enhance hydrolyzability, but cellulase usually acts on the surface of solid cellulose [30]. Surface morphology visually showed changes in the solid surface structure as well as the morphological structures of untreated RS, Fenton-RS and Fenton + B-8-RS fractions as captured by SEM in Fig. 3. The untreated RS has a regular and intact morphology with a smooth and compact surface. When exposed to the Fenton reagents, the smooth surface of the RS was completely broken and formed a lot of mesh gullies. The partially separated fiber and obviously collapsed framework presented loose RS. This suggested that the Fenton reactions caused rapid depolymerization on the surface, but the cellulose structure was not exposed. After B-8 pretreatment, the mesh portion on the surface of the RS became smooth. The hemicellulose and lignin were partially removed, leaving a loose lamellar structure. The raised portion of the surface mesh formed by the Fenton reaction might became the "landing point" of B-8. Thus, B-8 further modified the RS surface.

Nanometer-scale AFM was used to image RS to observe more details of the surface changes after pretreatment in Fig. 4. In the 3D image, the untreated RS presented a smooth surface, and the surface morphology of RS became noticeably rough after pretreatment. For quantitative analysis, the roughness average $\left(R_{\mathrm{a}}\right)$ and the maximum vertical distance between the highest and lowest data points $\left(R_{\max }\right)$ in the AFM image are listed in Table 2. All the roughness parameters increased significantly due to pretreatment with Fenton or Fenton + B-8.

Generally, in the AFM amplitude images, the tip adhered more strongly to the hydrophilic area, which appeared lighter in color [31]. Untreated RS surfaces were predominantly hydrophobic (indicated by darker phase images). This was the main reason for its low digestibility. Images taken after Fenton pretreatment of the outer cell wall phase showed several lighter patches that corresponded to regions abundant in hydrophilic species. This increased the availability of the enzymes. Correspondingly, the $R_{\mathrm{a}}$ and $R_{\max }$ of the Fenton-RS were 5.17 and 6.23 times higher than untreated RS, respectively. A thin layer of deposits (likely hemicellulosic polymers) covered the surface. Moreover, the hydrophobic lignin droplets observed after acidic pretreatments were also seen on RS surfaces [32]. This was attributed to lignin migration to the outer surface, and the surface lignin droplets were easily removed due to the reduced binding to carbohydrate polymers. In fact, the color of the treated RS became dark brown, which confirmed this point. After Fenton + B-8 pretreatment, the globular shapes of the deposited lignin decreased, possibly because of the effects of B-8 on lignin droplets. The modified lignin was depolymerized to lower lignin contents. Some of this was utilized by B-8. The roughness parameters of RS-Fenton + B-8 were still much higher than those of the RS-control, and the $R_{\mathrm{a}}$ of RS-Fenton $+\mathrm{B}-8$ was slightly above the RS-Fenton. In addition, the reduction of $R_{\max }$ was due to the role of $\mathrm{B}-8$, which changed the height distribution of the RS surface. There was a clear movement of the height distribution peak toward lower classes, just as the B-8 trimmed the raised surface.

The variations in the SSA and PV were identified by $\mathrm{N}_{2}$ sorption at $77 \mathrm{~K}$. Table 2 showed that both the SSA and PV of the pretreated RS increased obviously. For Fenton pretreatment, the increase in SSA due to the destruction of the lignocellulose structure by the free radical provided a greater surface area for subsequent bacterial treatment. After B-8 pretreatment, the increase in SSA and PV resulted from the depolymerization of lignin droplets and solubilization of the hemicellulose. The higher SSA and PV gave enhanced interfacial interactions between RS and the enzymes. This led to improved digestibility.
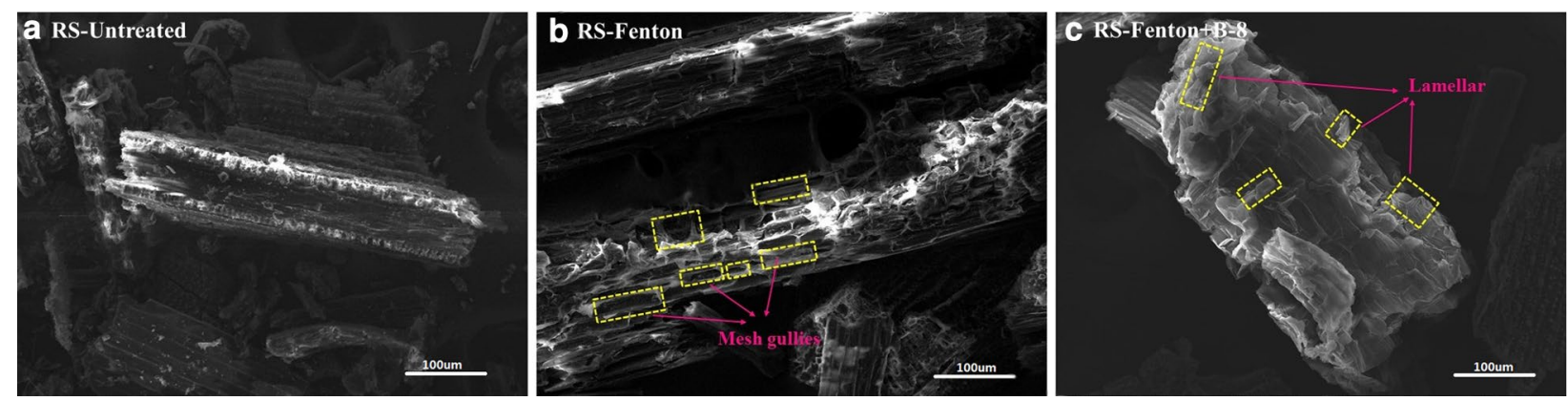

Fig. 3 SEM images of the untreated and pretreated RS. a The untreated RS had a regular and intact morphology. b After Fenton pretreatment, the compact surface of RS was completely broken and formed a lot of mesh gullies. c After B-8 pretreatment, RS appeared a loose lamellar structure 


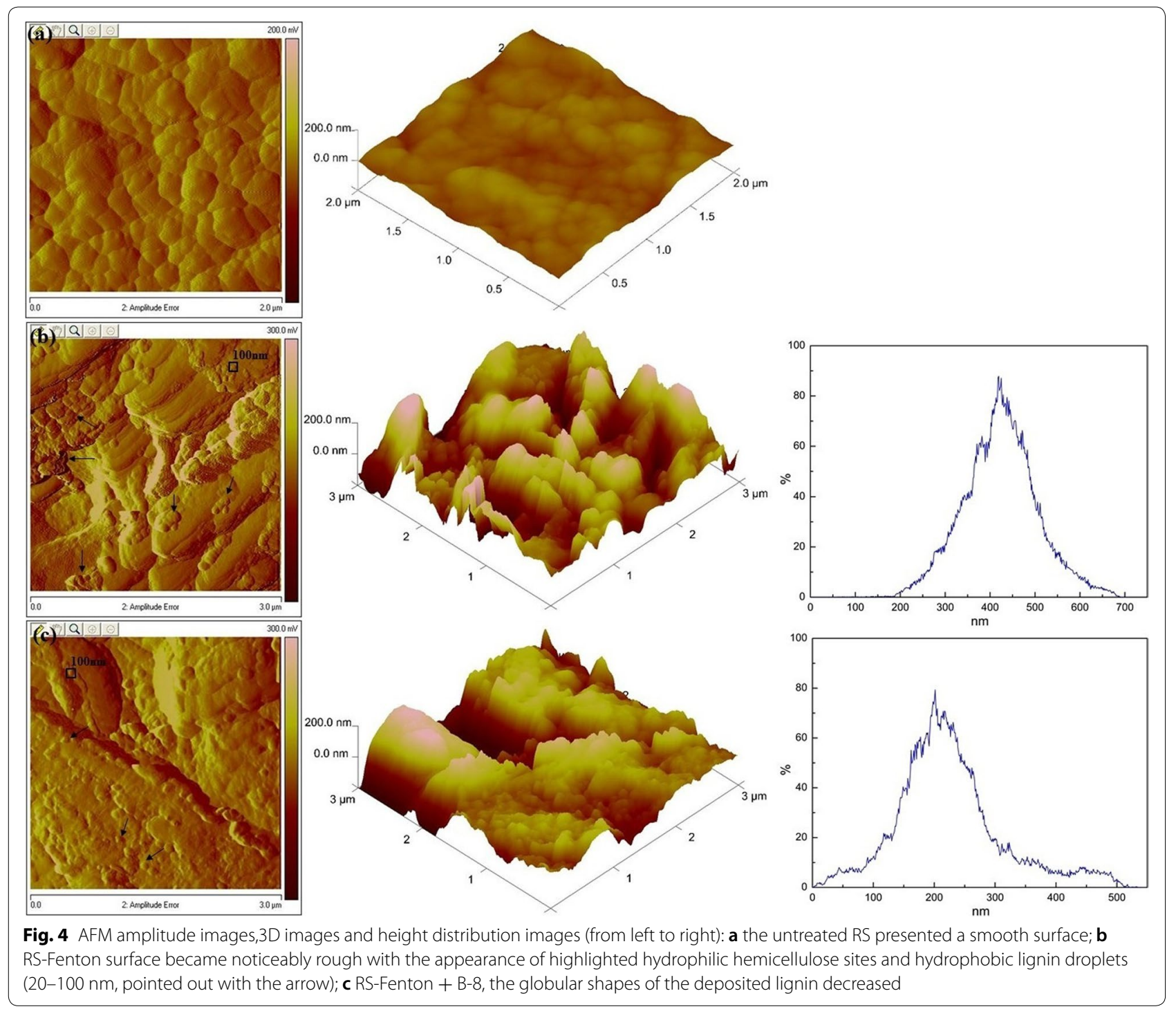

Table 2 Physiochemical characteristics of untreated and pretreated $\mathrm{RS}$

\begin{tabular}{llllll}
\hline RS & Crystallinity $^{\mathbf{a}}$ & $\begin{array}{l}\boldsymbol{R}_{\mathbf{a}} \\
(\mathbf{n m})^{\mathbf{b}}\end{array}$ & $\begin{array}{l}\boldsymbol{R}_{\mathbf{m a x}} \\
(\mathbf{n m})^{\mathbf{b}}\end{array}$ & $\begin{array}{l}\text { SSA } \\
\left(\mathbf{m}^{\mathbf{2}} \mathbf{g}^{-\mathbf{1}} \mathbf{)}^{\mathbf{c}}\right.\end{array}$ & $\begin{array}{l}\mathbf{P V} \\
\left(\mathbf{c m}^{\mathbf{3}} \mathbf{g}^{-\mathbf{1}} \mathbf{c}^{\mathbf{c}}\right.\end{array}$ \\
\hline Untreated & 0.489 & 12.4 & 111 & 0.647 & 0.0021 \\
Fenton & 0.575 & 64.2 & 692 & 0.936 & 0.0023 \\
$\begin{array}{c}\text { Fenton }+ \\
\text { B-8 }\end{array}$ & 0.644 & 64.6 & 523 & 0.967 & 0.0033 \\
\end{tabular}

a Crystallinity calculated from XRD analysis. ${ }^{\mathrm{b}} R_{\mathrm{a}}$ : average surface area roughness; $R_{\max }$ : the maximum vertical distance between the highest and lowest data points in the AFM image. ${ }^{~}$ SSA: specific surface area; PV is the total pore volume calculated from $B E T$ analysis

The XRD assay was a reliable method to evaluate RS structural transformation. XRD patterns of untreated and pretreated RS were presented in Fig. 5. The main diffraction peaks of $16.1^{\circ}$ and $22.1^{\circ}$ were assigned to the crystalline structures of cellulose I (101) and (002), respectively [33]. The calculated crystallinity index (CrI) values were $0.489,0.575$ and 0.644 for untreated RS, Fenton-RS and Fenton + B-8-RS, respectively. After the Fenton reaction, the crystallinity increased by $17.6 \%$, which suggested that pretreatments removed some amounts of the non-crystalline components. The RS structure that composed the crystalline regions was recalcitrant and was not easily destroyed by the Fenton reagent. Lignin migration to the outer surface exposed the internal cellulose surfaces, which increased the proportion of crystalline cellulose. After B-8 treatment, the crystallinity slightly increased to 0.644 . The increase in cellulose CrI was due to the amorphous hemicellulose and lignin was partially removed. The lignin and crosslinked 


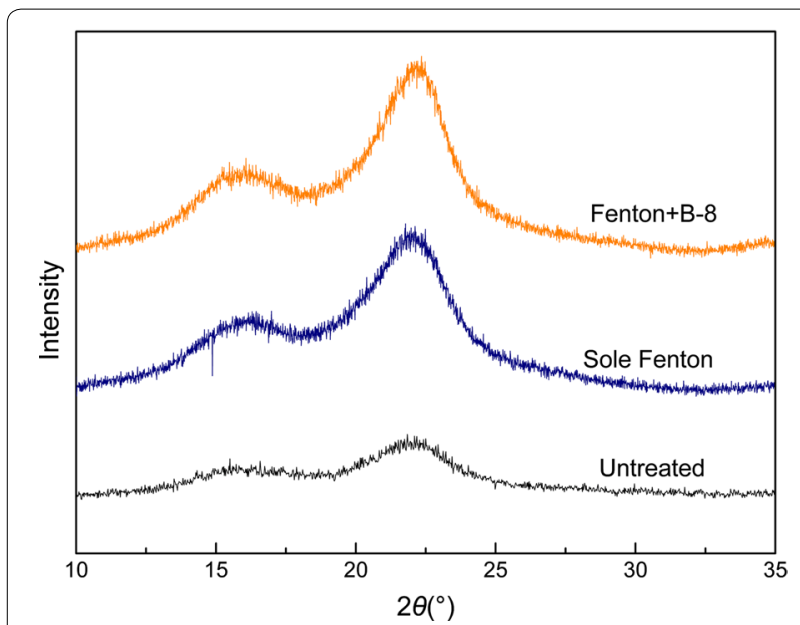

Fig. 5 XRD patterns of the untreated and pretreated RS samples: the main diffraction peaks of $16.1^{\circ}$ and $22.1^{\circ}$ were assigned to the crystalline structures of cellulose I (101) and (002), respectively

hemicellulose hindered hydrolysis in RS were stepwise destroyed by the Fenton + B- 8 pretreatment.

Based on these results, we hypothesized that the Fenton pretreatment destroyed the recalcitrant structure of RS that was difficult to be bio-activated. The increased surface roughness formed many hydrophilic sites that facilitated cell adhesion and growth. The B-8 then rapidly attached to the hemicellulose hydrophilic sites and acted on the lignin droplets exposed on the surface.
The removed lignin and hemicellulose content further enhanced the hydrolysis.

\section{Changes in chemical structure caused by pretreatment}

The FTIR spectra of untreated RS, Fenton-RS and Fenton + B-8-RS were presented in Fig. 6a. The broad bands in the $3400-3300 \mathrm{~cm}^{-1}$ region were $\mathrm{O}-\mathrm{H}$ stretching vibrations of cellulose, and the band at $2920 \mathrm{~cm}^{-1}$ was attributed to the $\mathrm{C}-\mathrm{H}$ stretching within the methylene of cellulose [34]. The $\mathrm{OH}$ bending of adsorbed water was at $1639 \mathrm{~cm}^{-1}$, and the typical of $\beta$-glycosidic bonds in cellulose was at $897 \mathrm{~cm}^{-1}$ [35]. After Fenton pretreatment, the intensity of cellulose characteristic peaks significantly decreased. This indicated that the structure of cellulose was destroyed by free radicals. However, the intensity of these cellulose bands increased after B-8 pretreatment, revealing that cellulose was well-preserved in B-8 pretreatment. The intensity of the shoulder peak at $1736 \mathrm{~cm}^{-1}$ which associated with the carbonyl band $(\mathrm{C}=\mathrm{O})$ in lignin and/or hemicelluloses had been increased, corresponding to an increase in hemicellulose content by Fenton pretreatment. In addition, the intensity of the peaks representing the lignin aromatic ring structure also showed changes, including aromatic ring $\mathrm{C}=\mathrm{C}$ stretching at $1648 \mathrm{~cm}^{-1}, \mathrm{C}-\mathrm{O}$ stretching at $1512 \mathrm{~cm}^{-1}$, and aromatic skeletal vibrations at $1427 \mathrm{~cm}^{-1}$. After Fenton pretreatment, the intensity of these lignin characteristic peaks decreased, indicating that lignin was partly destroyed and removed. However, these peaks were

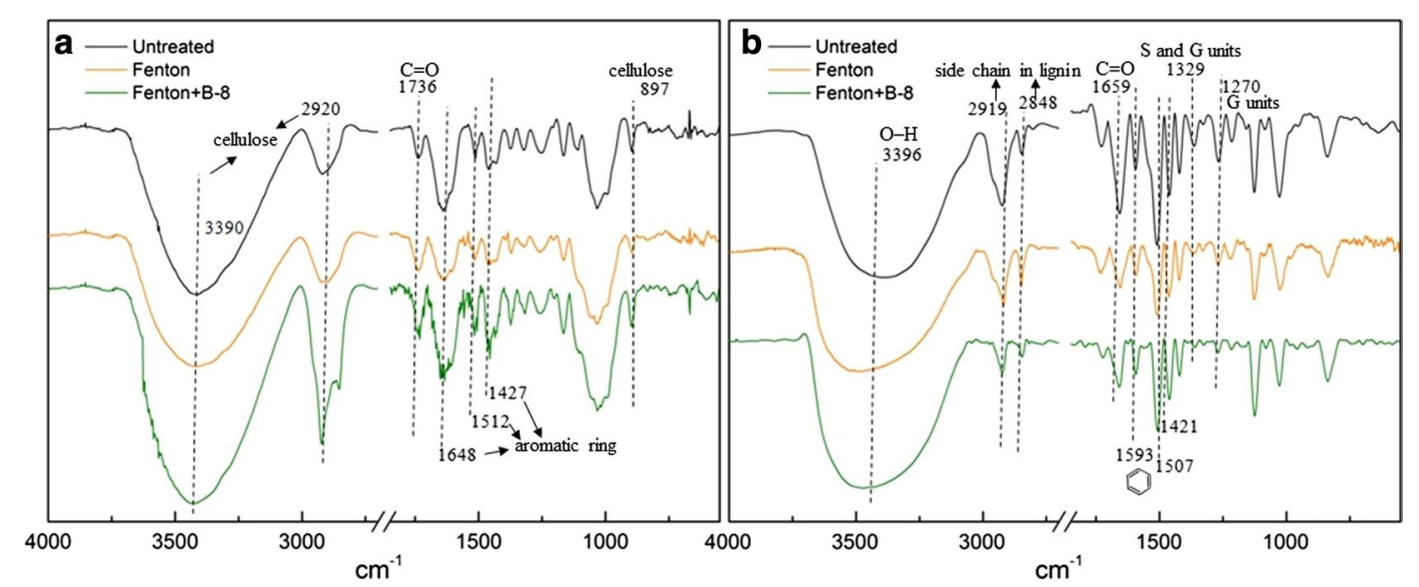

Fig. 6 FTIR spectra of untreated and pretreated RS and lignin samples. a FTIR spectra of RS samples. The broad bands in the $3400-3300 \mathrm{~cm}^{-1}$ region, the band at 2920 and $897 \mathrm{~cm}^{-1}$ were cellulose characteristic peaks. The shoulder peak at $1736 \mathrm{~cm}^{-1}$ which associated with the carbonyl band $(C=O)$ in lignin and/or hemicelluloses. The peaks at 1648,1512 and $1427 \mathrm{~cm}^{-1}$ representing the lignin aromatic ring structure. b FTIR spectra of isolated lignin from RS samples. The shoulder peak at $3396 \mathrm{~cm}^{-1}$ derived from the O-H stretching. The absorption peaks at 2919 and $2848 \mathrm{~cm}-1$ were the structure of the side chain in lignin. The peak at $1659 \mathrm{~cm}^{-1}$ derived from conjugated carbonyl $(C=O)$. The characteristic peaks of the benzene ring skeleton appeared at 1593, 1507 and $1421 \mathrm{~cm}^{-1}$. The absorption peaks of $\mathrm{S}$ units and condensed $\mathrm{G}$ units at $1329 \mathrm{~cm}^{-1} . \mathrm{G}$ units $\mathrm{C}=\mathrm{O}$ stretch at $1270 \mathrm{~cm}^{-1}$ 
enhanced after B-8 pretreatment, indicating that B-8 depolymerized lignin into small aromatic ring structures.

To further study the effects of B-8 on lignin, we extracted the lignin from RS. The FTIR spectra of lignin separated from untreated RS, Fenton-RS and Fenton + B-8-RS were presented in Fig. $6 \mathrm{~b}$. The spectra of lignin were similar before and after treatment only the absorption peak intensity was slightly different. This suggested that the overall structure of lignin was not destroyed to a large extent by chemical and bacterial pretreatment, only some chemical bonds were influenced. After Fenton pretreatment, the intensity of the shoulder peak at $3396 \mathrm{~cm}^{-1}$ derived from the $\mathrm{O}-\mathrm{H}$ stretching increased, which might be attributed to the role of demethoxylation. The absorption peaks at 2919 and $2848 \mathrm{~cm}^{-1}$ were from $\mathrm{C}-\mathrm{H}$ asymmetric and symmetrical stretching vibration of $\mathrm{CH}_{3}$ and $\mathrm{CH}_{2}$, respectively. This implied that the structure of the side chain in lignin was changed. The peak at $1659 \mathrm{~cm}^{-1}$ in the carbonyl region was derived from the absorption of the conjugated carbonyl $(\mathrm{C}=\mathrm{O})$. The characteristic peaks of the benzene ring skeleton appeared at 1593, 1507 and $1421 \mathrm{~cm}^{-1}$, and the decrease in those absorption peaks intensity indicated that the benzene ring structure of lignin was attacked by free radicals. In addition, both the absorption peaks of typical S units and/or condensed $\mathrm{G}$ units at $1329 \mathrm{~cm}^{-1}$ and $\mathrm{C}=\mathrm{O}$ stretch of $\mathrm{G}$ units at $1270 \mathrm{~cm}^{-1}$ also decreased. These changes of functional groups further proved that decomposition of the stable chemical structures of the residual lignin was extensive. After B-8 pretreatment, the hydroxyl structure, side chain structural unit, conjugated carbonyl and G units were all relatively reduced. These changes indicated that the modified lignin was depolymerized by B-8.

To further elucidate the lignin structure, two-dimensional hydrocarbon correlation spectra (2D-HSQC) analysis was carried out for characterization of the lignin from untreated and treated RS. The expanded spectra of the side chain and aromatic regions were shown in Figs. 7, 8. The data indicated that the overall structure of lignin was not drastically modified by the Fenton pretreatment, all the typical cross-signals of lignin remained visible. These included the well-resolved signals of $\beta-O$ $4^{\prime}(\mathrm{A}), \beta-\beta^{\prime}$ (resinol-type, B) and $\beta-5^{\prime}(\mathrm{C})$ side-chain linkages together with strong aromatic signals of syringyl (S), guaiacyl $(\mathrm{G})$ and $p$-hydroxyphenyl $(\mathrm{H})$ lignin units. However, the relative intensities of some chemical bonds were apparently affected. Minor spirodienones (D) were not detected. The relative abundance of the main inter-unit linkages (given as per aromatic units and as percentage of total side-chains involved) were calculated based on the HSQC spectra (Additional file 2: Table S1). Abundances of lignin side-chain linkages and ratio of $\mathrm{H}, \mathrm{G}$ and $\mathrm{S}$ were presented in Table 3.
After Fenton pretreatment, the data indicated that the relative abundances of the $\beta-O-4^{\prime}$ substructures were significantly reduced (from 81.3 to $76.2 \%$ of the total sidechains), and free radicals also modified that of the $\beta-\beta^{\prime}$ substructures (increased by $6.4 \%$ of total side-chains). The relative abundances of $\beta-5^{\prime}$ substructures decreased slightly (from $7.9 \%$ to $6.6 \%$ of total side-chains), the signal of $\mathrm{C}_{\gamma}-\mathrm{H}_{\gamma}$ in $\beta-\beta^{\prime}$ (resinol) (B) almost disappeared, and a new signal for $\mathrm{C}_{\beta}-\mathrm{H}_{\beta}$ in $\beta-\beta^{\prime}$ was found. This indicated that the $\beta-O-4^{\prime}$ substructures were broken, and lignin was partially depolymerized by the Fenton reaction. As mentioned above, the Fenton reaction removed $36 \%$ of the lignin, meaning that the Fenton pretreatment destroyed a large amount of $\beta-O-4^{\prime}$ substructures. However, a small increase in the oxygenated moieties was seen in the HSQC spectrum via the small signal corresponding to aliphatic $\mathrm{C}_{\alpha}-\mathrm{H}_{\alpha}$ correlation in $\mathrm{C}_{\alpha}$-oxidized $\beta-O-4^{\prime}$ substructures (E). This revealed that some oxidative alterations in the lignin structure occurred. The methoxyl peak at $\delta \mathrm{C} / \delta \mathrm{H} 54-57 / 3.1-4.5 \mathrm{ppm}$ also decreased, indicating that the radicals attacked lignin aromatic rings to cause demethylation, which was consistent with other studies [19]. The polysaccharide signals and possible lignin-carbohydrate linkages LCCs $(\delta \mathrm{C} /$ $\delta \mathrm{H}$ 65.7-79.3/2.8-3.7 ppm) were disappeared, demonstrating that carbohydrates in the RS lignin were almost depolymerized. And, lignin's close association with hemicellulose was disrupted by the Fenton reagents. In the aromatic region, the change in S/G ratio is an important indicator for characterizing lignin structure change during pretreatment (Table 3). The reduction in the S/G ratio (2.17-1.83) implies that the Fenton pretreated lignin had a smaller molecular weight. The aromatic $\mathrm{C}_{2}-\mathrm{H}_{2}$ and $\mathrm{C}_{6}-$ $\mathrm{H}_{6}$ correlation signal in $\mathrm{C}_{\alpha}$-oxidized $\mathrm{S}$ units $\left(\mathrm{S}^{\prime}\right)$ was also comparatively lower. The signal strength of the $\mathrm{S}$ and $\mathrm{G}$ units were reduced, perhaps because the $S$ unit or $G$ unit had been demethylated to form a common condensed $\mathrm{H}$-type unit. Moreover, the increased $\mathrm{H}$ units increased the accessibility of hydrolytic agents, as the $\mathrm{H}$ units were essentially all terminal [36].

After B-8 treatment, the relative abundance of the $\beta-O-4^{\prime}$ substructures decreased slightly (from 76.2 to $71.6 \%$ of total side-chains). The reduction also occurred on the $\beta-\beta^{\prime}$ substructures. The signal of $C_{\beta}-H_{\beta}$ in $\beta-\beta^{\prime}$ (resinol) (B) disappeared, accompanied by a significant increase in the structure of $\beta-5^{\prime}$ (from 6.6 to $13.5 \%$ of total side-chains). The signals of $\mathrm{B}_{\alpha}$ and $\mathrm{C}_{\alpha}$ showed comparatively higher intensity. This implies that B-8 mainly broke down the lignin formed by $\beta-O-4^{\prime}$ substructures. The $\beta-O-4^{\prime}$ substructures were mainly composed of $\mathrm{S}$ units, and the broken $\beta-O-4^{\prime}$ substructures might be transformed into $\beta-5$ substructures. The peaks of $\mathrm{C}_{2}-$ $\mathrm{H}_{2}$ and $\mathrm{C}_{6}-\mathrm{H}_{6}$ in oxidized $\mathrm{S}$ units $\left(\mathrm{S}^{\prime}\right)$ increased in the 
Zhang et al. Biotechnol Biofuels (2018) 11:31

Page 10 of 14

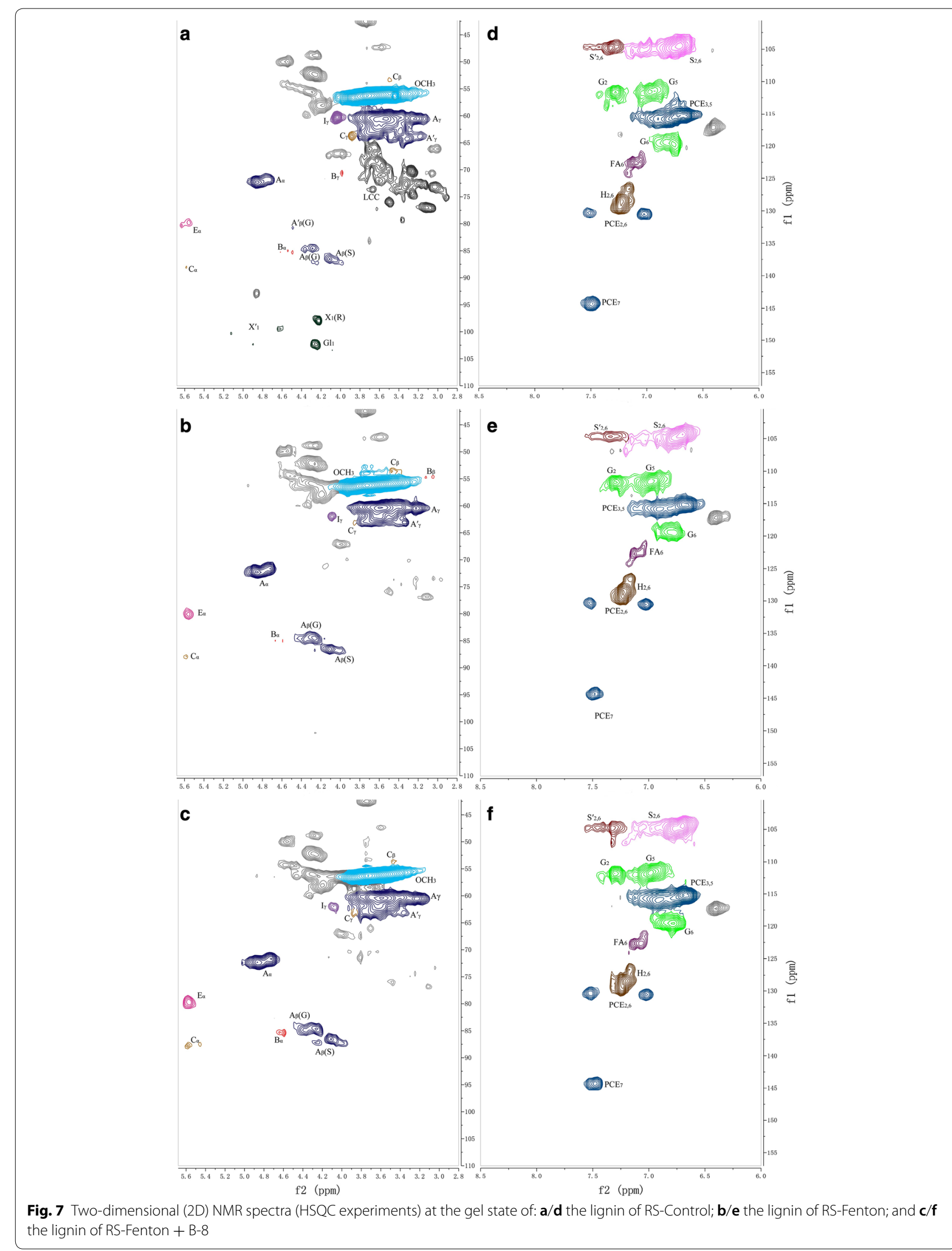



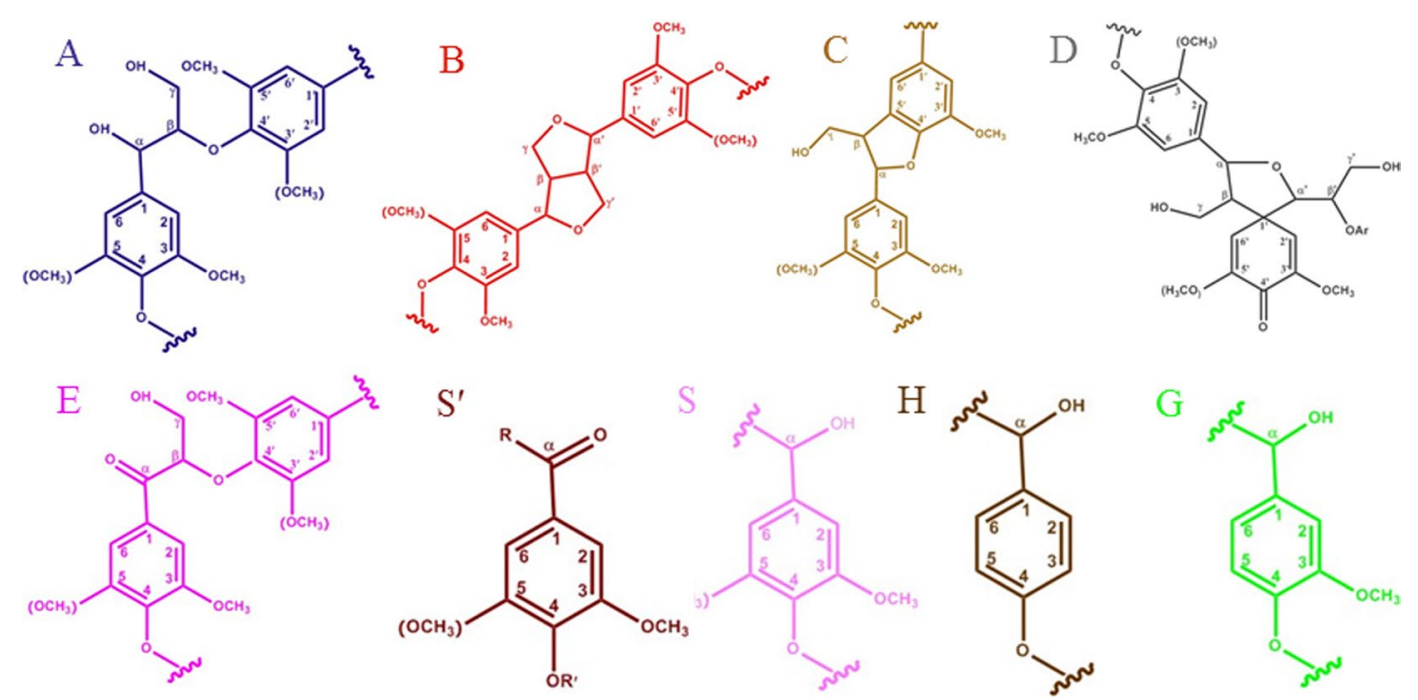

Fig. 8 Two-dimensional (2D) NMR spectra (HSQC experiments) at the gel state of: the lignin structures identified are shown: (A) $\beta-O-4^{\prime}$ substructure; (B) resinol substructure; (C) phenylcoumaran substructure; (D) spirodienone substructure; (G) guaiacyl unit; (S) syringyl unit; $\left(S^{\prime}\right) C_{a}$-oxidized $S$ unit; (E) $a, \beta$-diaryl ether substructures; $(\mathrm{H})$ para-hydroxy-phenyl unit ( $\mathrm{R}$, lignin or $\mathrm{OH} ; \mathrm{R}^{\prime}, \mathrm{H}$ or lignin)

Table 3 Semi-quantitative of the lignin polymer in the untreated and pretreated RS

\begin{tabular}{llll}
\hline & Untreated & Sole-Fenton & Fenton + B-8 \\
\hline$\beta-O-4^{\prime}$ aryl ethers (A) & 81.3 & 76.2 & 71.6 \\
$\beta-\beta^{\prime}$ resinols (B) & 10.8 & 17.2 & 14.9 \\
$\beta-5^{\prime}$ phenylcoumarans (C) & 7.9 & 6.6 & 13.5 \\
$\beta-1^{\prime}$ spirodienones (D) & 0 & 0 & 0 \\
Lignin aromatic unit $^{\mathrm{a}}$ & & & \\
$\mathrm{H}(\%)$ & 6.1 & 7.8 & 9.3 \\
$\mathrm{~S}(\%)$ & 64.3 & 59.7 & 59.9 \\
$\mathrm{G}(\%)$ & 29.6 & 32.5 & 30.8 \\
$\mathrm{~S} / \mathrm{G}$ ratio & 2.17 & 1.83 & 1.94 \\
\hline
\end{tabular}

${ }^{a}$ Molar percentages $(\mathrm{H}+\mathrm{G}+\mathrm{S}=100)$

aromatic region; other signals did not change significantly. Besides, the G-type lignin unit linked by $\beta$-aryl ether was more easily depolymerized and dissolved in the medium than the S-type by B-8 pretreatment process. Thus, the ratio of $S / G$ increased slightly. In previous research, we confirmed that the $\beta$-ketoadipate central pathway for ferulate degradation existed in B-8 by genomic analysis [37]. Ferulate served as the model compound for $\mathrm{G}$ units. In conclusion, the Fenton pretreatment caused partial depolymerization of lignin mainly by cleaving the $\beta-O-4$ linkage and by demethoxylation to remove the $\mathrm{S}$ and $\mathrm{G}$ units. B-8 could depolymerize amount of the $G$ units by cleaving the $\beta-5$ linkages that interconnect the lignin subunits.
Summary of the mechanism of Fenton + B-8 pretreatment In summary, these analyses supported the hypothetical biomimetic mechanism which is depicted in Fig. 9. Fenton pretreatment simulated rapid fungal erosion of biomass, and changed the surface morphology of the RS, such that the increase in roughness and hydrophilic sites enhanced lignocellulose bioavailability. Free radicals cleaved the internal glycosidic bonds of cellulose and hemicellulose, caused fiber surface oxidation, and disrupted lignin's close association with hemicellulose. Simultaneously, the lignin droplets migrated to the surface; lignin inter-unit linkages were cleaved by Fenton pretreatment which was conducive to further depolymerization of lignin by bacteria. In addition, lignin can absorb iron to form lignin-metal complexes through spontaneous chelation [19]. The lignin-metal complex may act as a capping agent to inhibit lignin re-condensation [19]. When bacterial cells were inoculated into this system, they adhered to the surface of the RS. Bacteria harbor versatile pathways for metabolizing complex substances, including recalcitrant aromatic substances ranging from simple phenols to the highly complex lignin polymer. Laccase, lignin peroxidase, and manganese peroxidase are the most well-studied enzymes involved in lignin degradation [38]. In our previous work, gene sequence and enzyme activity of a laccase has been confirmed in B-8 [37]. Laccase can degrade and/or dissolve the lignin to form a mixture of oxidative degradation products [37]. The laccase system is reported preferentially to attack phenolic substrates, 


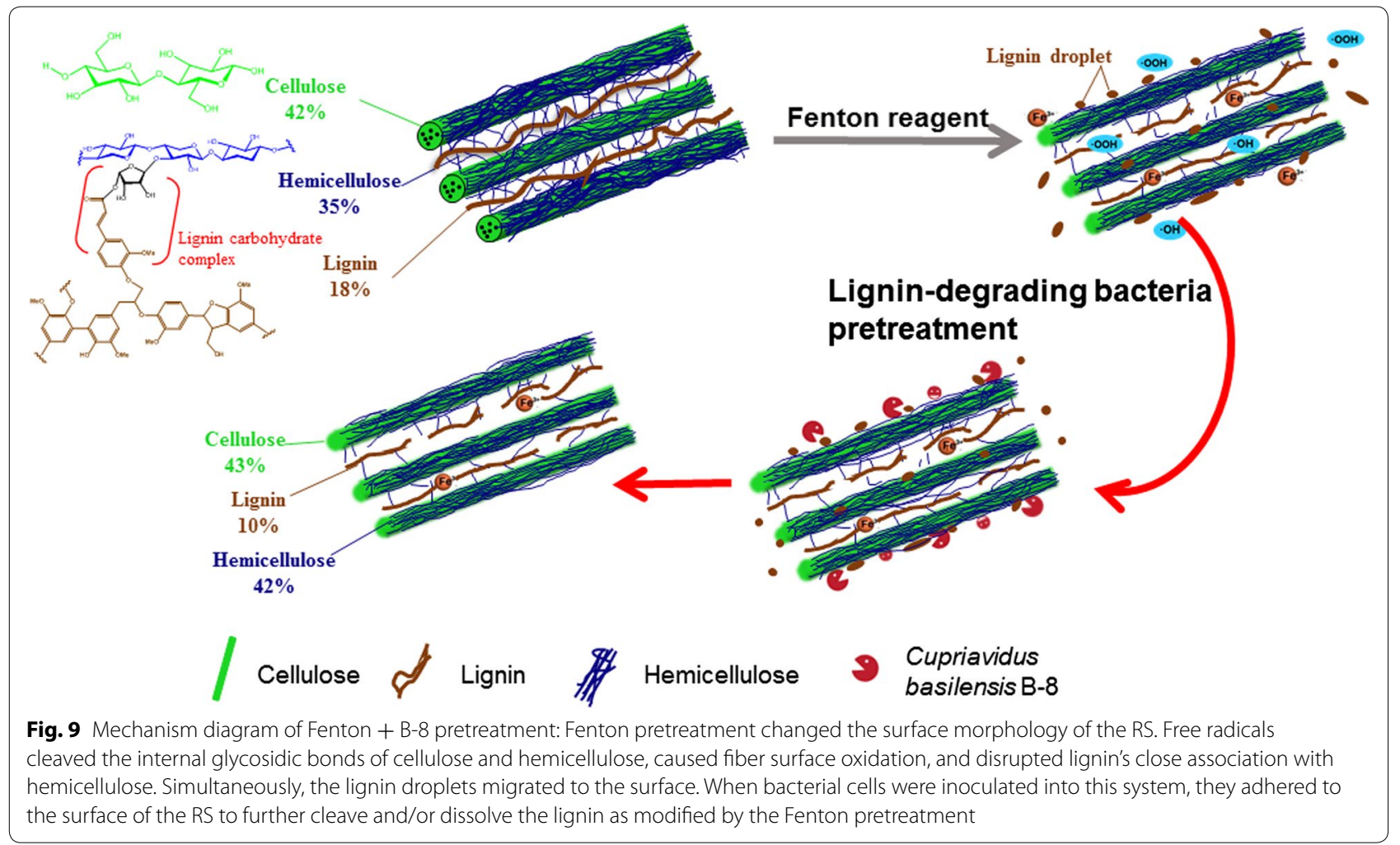

and it can self-generate radicals by releasing the phenolic compounds from lignin to create a sustainable redox environment to achieve lignin depolymerization and modification [39]. The demethoxylation of Fenton reaction formed more phenolic hydroxyl groups. Consequently, the B-8 used a laccase system to further cleave and/or dissolve the lignin as modified by the Fenton pretreatment. Generally, lignin with higher guaiacyl content absorbs more cellulase [40]. In particular, B-8 could depolymerize amount of the G units as shown by the 2D NMR analysis and genomic analysis [37]. In addition, the B-8 also had a positive effect on the removal of the hemicellulose, according to the results of the component analysis. This eventually exposed more fibers for cellulose binding and further improved the sugar release.

\section{Conclusions}

A biomimetic system with a biochemical Fenton reaction and lignocellulose-degrading bacteria was confirmed to be able to pretreatment of RS to enhance enzymatic hydrolysis under mild conditions. The enzymatic hydrolysis results showed that the maximum increase in the digestibility was $56.6 \%$ by Fenton + B- 8 pretreatment compared with that by Fenton pretreatment alone. Such high digestibility was attributed to the destruction of lignin structure, partial hydrolysis of hemicellulose and partial surface oxidation of cellulose. Multiple detailed physical and chemical characterization steps of RS elaborated the mechanism. This system provided a new insight into the design of more effective strategies for the pretreatment of lignocellulosic biomass.

\section{Additional files}

Additional file 1: Figure S1. The effects of pretreatment conditions on the enzymatic hydrolysis of the untreated (dashed line) and pretreated RS. The experimental groups were $\mathrm{A}: 0.04 \mathrm{M} \mathrm{FeCl}_{3} / 0.04 \mathrm{M} \mathrm{FeCl}_{2} / 3 \mathrm{M} \mathrm{H}_{2} \mathrm{O}_{2} ; \mathrm{B}$ : $0.03 \mathrm{M} \mathrm{FeCl}_{3} / 0.03 \mathrm{M} \mathrm{FeCl}_{2} / 2.25 \mathrm{M} \mathrm{H}_{2} \mathrm{O}_{2} ; \mathrm{C}: 0.02 \mathrm{M} \mathrm{FeCl}_{3} / 0.02 \mathrm{M} \mathrm{FeCl}_{2} / 1.5 \mathrm{M}$ $\mathrm{H}_{2} \mathrm{O}_{2} ; \mathrm{D}: 0.01 \mathrm{M} \mathrm{FeCl}_{3} / 0.01 \mathrm{M} \mathrm{FeCl}_{2} / 0.75 \mathrm{M} \mathrm{H}_{2} \mathrm{O}_{2}$

Additional file 2: Table S1. Assignment of lignin and polysaccharide correlation signals in the HSQC spectra shown in Figs. 7, 8.

\section{Abbreviations}

B-8: Cupriavidus basilensis B-8; RS: rice straw; 2D-NMR: 2D-nuclear magnetic resonance; SEM: scanning electron microscope; AFM: atomic force microscopy; BET: BET specific surface area test method; XRD: X-ray diffraction; Crl: crystallinity index; FTIR: Fourier transform infrared spectroscopy; LCCs: lignincarbohydrate linkages; $R_{\mathrm{a}}$ : average surface area roughness; $R_{\max }:$ maximum vertical distance between the highest and lowest data points; SSA: specific surface area; PV: pore volume.

\section{Authors' contributions}

YS and YX developed the idea for the study. KZ designed the research, analyzed the result and prepared the manuscript. YS, YX and HL helped to revise 
the manuscript. MS, DL, SZ and ML helped to do the lab work. All authors read and approved the final manuscript.

\section{Author details}

${ }^{1}$ School of Metallurgy and Environment, Central South University, Changsha 410083, People's Republic of China. ${ }^{2}$ Chinese National Engineering Research Center for Control \& Treatment of Heavy Metal Pollution, Changsha 410083, People's Republic of China.

\section{Acknowledgements}

This work was supported by Program for Changjiang Scholars (T2011116), National Funds for Distinguished Young Scientists of China (50925417), key project of National Natural Science Foundation of China (51634010), National Natural Science Foundation of China (31400115), Special Program on Environmental Protection for Public Welfare (201509050), China Postdoctoral Science Foundation (2017M612594), and Postdoctoral Science Foundation of Central South University (140050002).

\section{Competing interests}

The authors declare that they have no competing interests.

\section{Availability of data and materials}

The datasets used and/or analyzed during the current study are available from the corresponding author on reasonable request.

\section{Consent for publication}

Not applicable.

\section{Ethics approval and consent to participate}

Not applicable.

\section{Publisher's Note}

Springer Nature remains neutral with regard to jurisdictional claims in published maps and institutional affiliations.

\section{Received: 17 October 2017 Accepted: 27 January 2018}

Published online: 08 February 2018

\section{References}

1. Zeikus JG. Lignin metabolism and the carbon cycle. New York: Springer US; 1981

2. Pu YQ, Hu F, Huang F, Davison BH, Ragauskas AJ. Assessing the molecular structure basis for biomass recalcitrance during dilute acid and hydrothermal pretreatments. Biotechnol Biofuels. 2013;6:15.

3. Isikgor F, Becer CR. Lignocellulosic biomass: a sustainable platform for the production of bio-based chemicals and polymers. Polym Chem. 2016;6:4497-559

4. Himmel ME, Ding SY, Johnson DK, Adney WS, Nimlos MR, Brady JW, Foust TD. Biomass recalcitrance: engineering plants and enzymes for biofuels production. Science. 2007:315:804-7.

5. Gong ZW, Shen HW, Wang Q, Yang XB, Xie HB, Zhao ZBK. Efficient conversion of biomass into lipids by using the simultaneous saccharification and enhanced lipid production process. Biotechnol Biofuels. 2013;6:36.

6. Yelle DJ, Wei D, John R, Hammel KE. Multidimensional NMR analysis reveals truncated lignin structures in wood decayed by the brown rot basidiomycete Postia placenta. Environ Microbiol. 2011;13:1091-100.

7. Rahimi A, Ulbrich A, Coon JJ, Stahl SS. Formic-acid-induced depolymerization of oxidized lignin to aromatics. Nature. 2014;515:249-52.

8. Crawford DL, Crawford RL. Microbial degradation of lignocellulose: the lignin component. Appl Environ Microbiol. 1976;31:714-7.

9. Gellerstedt G, Henriksson G: Lignins: major sources, structure and properties. In: Monomers polymers \& composites from renewable resources. 2008. p. 201-24.

10. Millati R, Syamsiah S, Niklasson C, Cahyanto MN, Lundquist K, Taherzadeh MJ. Biological pretreatment of lignocelluloses with white-rot fungi and its applications: a review. Bioresources. 201 1;6:5224-59.

11. Martinez D, Larrondo LF, Putnam N, Gelpke MDS, Huang K, Chapman J, Helfenbein KG, Ramaiya P, Detter JC, Larimer F. Genome sequence of the lignocellulose degrading fungus Phanerochaete chrysosporium strain RP78. Nat Biotechnol. 2004;22:695-700.

12. Bhatia SK, Kim SH, Yoon JJ, Yang YH. Current status and strategies for second generation biofuel production using microbial systems. Energy Convers Manag. 2017;148:1142-56.

13. Bugg TDH, Ahmad M, Hardiman EM, Rahmanpour R. Pathways for degradation of lignin in bacteria and fungi. Nat Prod Rep. 2011;28:1883-96.

14. Mathews SL, Pawlak J, Grunden AM. Bacterial biodegradation and bioconversion of industrial lignocellulosic streams. Appl Microbiol Biotechnol. 2015;99:2939-54.

15. Salvachua D, Katahira R, Cleveland NS, Khanna P, Resch MG, Black BA, Purvine SO, Zink EM, Prieto A, Martinez MJ, et al. Lignin depolymerization by fungal secretomes and a microbial sink. Green Chem. 2016;18:6046-62.

16. Rineau F, Roth D, Shah F, Smits M, Johansson T, Canbäck B, Olsen PB, Persson $\mathrm{P}$, Grell MN, Lindquist E. The ectomycorrhizal fungus Paxillus involutus converts organic matter in plant litter using a trimmed brown-rot mechanism involving Fenton chemistry. Environ Microbiol. 2012;14:1477-87.

17. Alper $\mathrm{H}$, Stephanopoulos $\mathrm{G}$. Engineering for biofuels: exploiting innate microbial capacity or importing biosynthetic potential? Nat Rev Microbiol. 2009:7:715-23.

18. Hildén L, Johansson G, Pettersson G, Li J, Ljungquist P, Henriksson G. Do the extracellular enzymes cellobiose dehydrogenase and manganese peroxidase form a pathway in lignin biodegradation? FEBS Lett. 2000;477:79-83.

19. Zeng JJ, Yoo CG, Wang F, Pan XJ, Vermerris W, Tong ZH. Biomimetic Fenton-catalyzed lignin depolymerization to high-value aromatics and dicarboxylic acids. Chemsuschem. 2015;8:861-71.

20. Banerjee G, Car S, Scott-Craig JS, Hodge DB, Walton JD. Alkaline peroxide pretreatment of corn stover: effects of biomass, peroxide, and enzyme loading and composition on yields of glucose and xylose. Biotechnol Biofuels. 2011:4:16.

21. Jung YH, Kim HK, Park HM, Park YC, Park K, Seo JH, Kim KH. Mimicking the Fenton reaction-induced wood decay by fungi for pretreatment of lignocellulose. Bioresour Technol. 2015;179:467-72.

22. Yan X, Wang Z, Zhang K, Si M, Liu M, Chai L, Liu X, Shi Y. Bacteriaenhanced dilute acid pretreatment of lignocellulosic biomass. Bioresour Technol. 2017;245:419-25.

23. Miller GL. Use of dinitrosalicylic acid reagent for determination of reducing sugar. Anal Biochem. 1959;31:426-8.

24. Teramoto Y, Tanaka N, Lee SH, Endo T. Pretreatment of eucalyptus wood chips for enzymatic saccharification using combined sulfuric acid-free ethanol cooking and ball milling. Biotechnol Bioeng. 2008;99:75-85.

25. Yan X, Li Q, Chai L, Yang B, Wang Q. Formation of abiological granular sludge - a facile and bioinspired proposal for improving sludge settling performance during heavy metal wastewater treatment. Chemosphere. 2014;113:36-41.

26. Chai L, Yan X, Li Q, Yang B, Wang Q. A comparative study of abiologica granular sludge (ABGS) formation in different processes for zinc removal from wastewater. Environ Sci Pollut Res. 2014;21:12436-44.

27. Wen JL, Sun SL, Yuan TQ, Sun RC. Structural elucidation of whole lignin from Eucalyptus based on preswelling and enzymatic hydrolysis. Green Chem. 2015;17:1589-96.

28. Gui X, Wang G, Hu M, Yan Y. Combined fungal and mild acid pretreatment of Glycyrrhiza uralensis residue for enhancing enzymatic hydrolysis and oil production. BioResources. 2013:8:5485-99.

29. Bhange VP, William SP, Sharma A, Gabhane J, Vaidya AN, Wate SR. Pretreatment of garden biomass using Fenton's reagent: influence of $\mathrm{Fe}^{2+}$ and $\mathrm{H}_{2} \mathrm{O}_{2}$ concentrations on lignocellulose degradation. J Environ Health Sci Eng. 2015;13:12.

30. Yuan ZQ, Long JX, Wang TJ, Shu RY, Qi Z, Ma LL. Process intensification effect of ball milling on the hydrothermal pretreatment for corn straw enzymolysis. Energy Convers Manag. 2015;101:481-8.

31. Chundawat SPS, Donohoe BS, Sousa LDC, Elder T, Agarwal UP, Lu F, Ralph J, Himmel ME, Balan V, Dale BE. Multi-scale visualization and characterization of lignocellulosic plant cell wall deconstruction during thermochemical pretreatment. Energy Environ Sci. 2011;4:973-84.

32. Kristensen JB, Thygesen LG, Felby C, Jørgensen H, Elder T. Cell-wall structural changes in wheat straw pretreated for bioethanol production. Biotechnol Biofuels. 2008;1:5.

33. Wu ZL, Zhang ML, Wang LQ, Tu YY, Zhang J, Xie GS, Zou WH, Li FC, Guo K, $\mathrm{Li} Q$, et al. Biomass digestibility is predominantly affected by three factors 
of wall polymer features distinctive in wheat accessions and rice mutants. Biotechnol Biofuels. 2013;6:183.

34. Singh R, Singh S, Trimukhe KD, Pandare KV, Bastawade KB, Gokhale DV Varma AJ. Lignin-carbohydrate complexes from sugarcane bagasse: preparation, purification, and characterization. Carbohydr Polym. 2005;62:57-66.

35. Saha S, Kurade MB, El-Dalatony MM, Chatterjee PK, Lee DS, Jeon BH. Improving bioavailability of fruit wastes using organic acid: an exploratory study of biomass pretreatment for fermentation. Energy Convers Manag. 2016;127:256-64.

36. Yelle DJ, Kaparaju P, Hunt CG, Hirth K, Kim H, Ralph J, Felby C. Twodimensional NMR evidence for cleavage of lignin and xylan substituents in wheat straw through hydrothermal pretreatment and enzymatic hydrolysis. Bioenergy Res. 2013;6:211-21.

37. Shi Y, Chai LY, Tang CJ, Yang ZH, Zhang H, Chen RH, Chen YH, Zheng Y. Characterization and genomic analysis of kraft lignin biodegradation by the beta-proteobacterium Cupriavidus basilensis B-8. Biotechnol Biofuels. 2013;6:1.

38. Majumdar S, Lukk T, Solbiati JO, Bauer S, Nair SK, Cronan JE, Gerlt JA. Roles of small laccases from streptomyces in lignin degradation. Biochemistry. 2014;53:4047-58.
39. Xie SX, Sun QN, Pu YQ, Lin FR, Sun S, Wang X, Ragauskas AJ, Yuan JS Advanced chemical design for efficient lignin bioconversion. Acs Sustain Chem Eng. 2017;5:2215-23.

40. Ko JK, Ximenes E, Kim Y, Ladisch MR. Adsorption of enzyme onto lignins of liquid hot water pretreated hardwoods. Biotechnol Bioeng. 2015;112:447-56

41. Jeong SY, Lee JW. Sequential Fenton oxidation and hydrothermal treatment to improve the effect of pretreatment and enzymatic hydrolysis on mixed hardwood. Bioresour Technol. 2016;200:121-7.

42. Shi J, Sharmashivappa RR, Chinn M, Howell N. Effect of microbial pretreatment on enzymatic hydrolysis and fermentation of cotton stalks for ethanol production. Biomass Bioenergy. 2009;33:88-96.

43. Dai YZ, Si MY, Chen YH, Zhang NL, Zhou M, Liao Q, Shi DQ, Liu YN. Combination of biological pretreatment with $\mathrm{NaOH} /$ Urea pretreatment at cold temperature to enhance enzymatic hydrolysis of rice straw. Bioresour Technol. 2015;198:725-31.

\section{Submit your next manuscript to BioMed Central and we will help you at every step:}

- We accept pre-submission inquiries

- Our selector tool helps you to find the most relevant journal

- We provide round the clock customer support

- Convenient online submission

- Thorough peer review

- Inclusion in PubMed and all major indexing services

- Maximum visibility for your research

Submit your manuscript at www.biomedcentral.com/submit
() Biomed Central 